Article

\title{
Highly Conductive and Transparent AZO Films Fabricated by PLD as Source/Drain Electrodes for TFTs
}

\author{
Hongke Zhang ${ }^{1}$, Xiaoqing $\mathrm{Li}^{1}{ }^{\text {, Zhiqiang Fang }}{ }^{2}{ }^{\mathbb{D}}$, Rihui Yao ${ }^{1, *} \mathbb{0}$, Xiaochen Zhang ${ }^{1}$, \\ Yuxi Deng ${ }^{1}$, Xubing Lu ${ }^{3}$, Hong Tao ${ }^{4}$, Honglong Ning ${ }^{1, *(D)}$ and Junbiao Peng ${ }^{1}$ \\ 1 Institute of Polymer Optoelectronic Materials and Devices, State Key Laboratory of Luminescent Materials \\ and Devices, South China University of Technology, Guangzhou 510640, China; \\ zhanghongkekeke@163.com (H.Z.); L_xiaoqing@163.com (X.L.); zhangxc_scut@foxmail.com (X.Z.); \\ dengyuxixi@163.com (Y.D.); psjbpeng@scut.edu.cn (J.P.) \\ 2 State Key Laboratory of Pulp and Paper Engineering, South China University of Technology, \\ Guangzhou 510640, China; fangzq1230@126.com \\ 3 Institute for Advanced Materials and Guangdong Provincial Key Laboratory of Quantum Engineering and \\ Quantum Materials, South China Normal University, Guangzhou 510006, China; luxubing@scnu.edu.cn \\ 4 Shenzhen Costar Technologies Co., Ltd., Shenzhen 518000, China; th@newvision-cn.com \\ * Correspondence: yaorihui@scut.edu.cn (R.Y.); ninghl@scut.edu.cn (H.N.)
}

Received: 19 October 2018; Accepted: 1 December 2018; Published: 6 December 2018

\begin{abstract}
Aluminum-doped $\mathrm{ZnO}(\mathrm{AZO})$ has huge prospects in the field of conductive electrodes, due to its low price, high transparency, and pro-environment. However, enhancing the conductivity of AZO and realizing ohmic contact between the semiconductor and AZO source/drain (S/D) electrodes without thermal annealing remains a challenge. Here, an approach called pulsed laser deposition (PLD) is reported to improve the comprehensive quality of AZO films due to the high energy of the laser and non-existence of the ion damage. The 80-nm-thick AZO S/D electrodes show remarkable optical properties (transparency: 90.43\%, optical band gap: $3.42 \mathrm{eV}$ ), good electrical properties (resistivity: $16 \times 10^{-4} \Omega \cdot \mathrm{cm}$, hall mobility: $3.47 \mathrm{~cm}^{2} / \mathrm{V} \cdot \mathrm{s}$, carrier concentration: $9.77 \times 10^{20} \mathrm{~cm}^{-3}$ ), and superior surface roughness $\left(\mathrm{R}_{\mathrm{q}}=1.15 \mathrm{~nm}\right.$ with scanning area of $\left.5 \times 5 \mu \mathrm{m}^{2}\right)$. More significantly, their corresponding thin film transistor (TFT) with low contact resistance $\left(R_{S D}=0.3 \mathrm{M} \Omega\right.$ ) exhibits excellent performance with a saturation mobility $\left(\mu_{\text {sat }}\right)$ of $8.59 \mathrm{~cm}^{2} / \mathrm{V} \cdot \mathrm{s}$, an $\mathrm{I}_{\text {on }} / \mathrm{I}_{\text {off }}$ ratio of 4.13 $\times 10^{6}$, a subthreshold swing (SS) of $0.435 \mathrm{~V} /$ decade, as well as good stability under PBS/NBS. Furthermore, the average transparency of the unpatterned multi-films composing this transparent TFT can reach $78.5 \%$. The fabrication of this TFT can be suitably transferred to transparent arrays or flexible substrates, which is in line with the trend of display development.
\end{abstract}

Keywords: AZO; PLD; TFT; transparency; source/drain electrodes

\section{Introduction}

Over the last decades, flexible and transparent electronics have attracted widespread attention. Numerous important studies on transparent materials and their application to devices have been published, especially towards the fabrication of transparent TFTs [1-5]. In all displays, less optical loss on transparent TFTs is unmatched. Well-designed TFTs will account for a cost reduction and life extension of displays [6,7].

Nowadays, the most commercially important material for transparent conducting material is indium tin oxide (ITO), owing to its brilliant properties of high visible transmittance $(90 \%)$, low direct-current (DC) resistivity, and high infra-red reflectance [8]. Nonetheless, ITO suffers from several 
drawbacks, including the cost and toxicity of indium [9]. Other transparent conducting oxides (TCOs) materials are being widely developed [10-12]. AZO has been regarded as a promising alternative to ITO, attributed to its abundant resources, low cost, and non-toxicity [12-17]. A large number of investigators have attempted to fabricate high-quality AZO films at room temperature by various measures [18-21]. Among these ways, PLD is a relatively good method for manufacturing high-quality AZO films at room temperature, owing to the high energy of the laser and non-existence of the ion damage. Moreover, the composition of the films deposited by PLD is almost the same as that of the target.

In this paper, we try to prepare transparent TFTs by employing AZO S/D electrodes. XRD, AFM, Hall, and UV measurements are used to investigate the performances of AZO films. As a result, AZO electrodes fabricated by PLD at room temperature exhibit superior resistivity, transparency, optical band gap, and surface roughness. More significantly, the optimum AZO (PLD-AZO) S/D electrodes are used to produce transparent TFTs without thermal annealing and their corresponding devices exhibit a $\mu_{\text {sat }}$ of $8.59 \mathrm{~cm}^{2} / \mathrm{V} \cdot \mathrm{s}$, an SS of $0.435 \mathrm{~V} /$ decade, an $\mathrm{I}_{\mathrm{on}} / \mathrm{I}_{\text {off }}$ ratio of $4.13 \times 10^{6}$, a high transmittance of $78.5 \%$, and excellent stability under PBS/NBS. Furthermore, the contact resistance of TFTs is as low as $0.3 \mathrm{M} \Omega$, resulting in better output characteristics.

\section{Experimental}

For convenience in this paper, PVD-AZO and PLD-AZO denote the AZO electrodes prepared by PVD and PLD, respectively. PVD-AZO-TFT and PLD-AZO-TT denote their corresponding TFTs. The picture of this transparent AZO film is presented in Figure 1b. 80-nm-thick AZO films were deposited by the PVD and PLD method on the glass substrate. PVD-AZO $\left(\mathrm{Al}_{2} \mathrm{O}_{3}: \mathrm{ZnO}=2: 98 \mathrm{wt} \%\right)$ was fabricated by radio frequency (RF) magnetron sputtering (Kurt J. Lesker, Jefferson Hills, PA, USA) at the optimized condition (atmosphere: Pure Ar, pressure: 1 mtorr, power: $80 \mathrm{~W})$. PLD-AZO $\left(\mathrm{Al}_{2} \mathrm{O}_{3}\right.$ : $\mathrm{ZnO}=2: 98 \mathrm{wt} \%$ ) was deposited by $\mathrm{PLD}$ at room temperature with an $\mathrm{O}_{2}$ flow rate of $0 \mathrm{sccm}$, a pulsing energy of $400 \mathrm{~mJ}$, a repeating rate of $5 \mathrm{~Hz}$, and a $\mathrm{KrF}$ laser wavelength of $248 \mathrm{~nm}$.
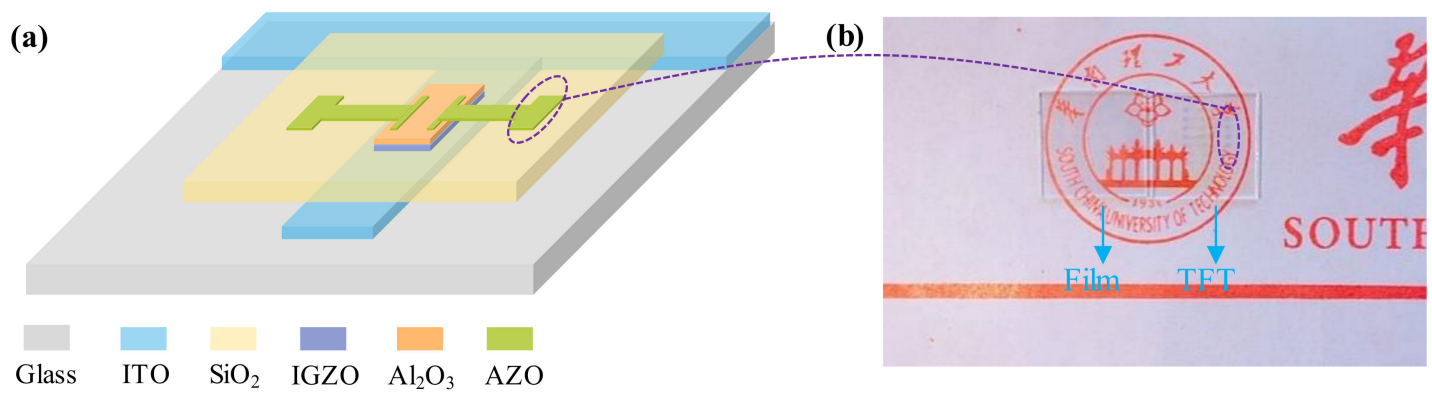

Figure 1. (a) Schematic illustration of the transparent TFTs with AZO S/D electrodes; (b) digital photo of transparent AZO film and corresponding TFTs.

A schematic illustration and picture of the transparent TFT with AZO S/D electrodes is presented in Figure 1a,b. 200-nm-thick ITO gate electrodes and a 200-nm-thick $\mathrm{SiO}_{2}$ gate insulator were prepared by PVD and PECVD. Then, a bi-layer of 9.5-nm-thick indium gallium zinc oxide (IGZO) and 3.5-nm-thick $\mathrm{Al}_{2} \mathrm{O}_{3}$ acted as an active layer, IGZO was deposited by pulse direct-current (DC) magnetron sputtering in mixed $\mathrm{Ar} / \mathrm{O}_{2}(100 / 5)$ atmosphere at a pressure of $1 \mathrm{mtorr}$ and power of $100 \mathrm{~W}$, and the pulsing frequency and reverse time for the pulse-DC mode were $10 \mathrm{kHz}$ and $10 \mu \mathrm{s}$. $\mathrm{Al}_{2} \mathrm{O}_{3}$ was deposited by RF sputtering in pure Ar atmosphere, the sputtering power and pressure were $120 \mathrm{~W}$ and 1 mtorr [22], respectively. Finally, 80-nm-thick PVD-AZO and PLD-AZO were adopted to the $S / D$ electrodes. The channel layer, gate insulator, $S / D$, and gate electrodes were all patterned by shadow masks. Additionally, S/D electrodes were fabricated at room temperature. 


\section{Results and Discussion}

The excellent electrical and optical properties of AZO film enable it to be potential S/D electrodes for transparent TFTs. Among these characteristics, the resistivity, transmittance, optical band gap, contact resistance, and surface topography of AZO film are the most critical parameters for its application in transparent displays. The respective parameters of PVD-AZO and PLD-AZO that we have obtained are summarized in Table 1.

Table 1. Performance parameters' comparison of AZO films deposited by PVD and PLD.

\begin{tabular}{ccccccc}
\hline Films & $\begin{array}{c}\text { Resistivity } \\
(\boldsymbol{\Omega} \mathbf{~ c m})\end{array}$ & $\begin{array}{c}\text { Hall Mobility } \\
\left(\mathbf{c m}^{2} / \mathbf{V} \cdot \mathbf{s}\right)\end{array}$ & $\mathbf{n}\left(\mathbf{c m}^{-3}\right)$ & Transmittance & $\begin{array}{c}\phi_{\text {TC }} \\
\left(\boldsymbol{\Omega}^{-1}\right)\end{array}$ & $\mathbf{E}_{\mathbf{g}}(\mathbf{e V})$ \\
\hline PVD-AZO & $2.64 \times 10^{-3}$ & 3.35 & $8.2 \times 10^{20}$ & $88 \%$ & $2.7 \times 10^{-3}$ & 3.3 \\
PLD-AZO & $1.6 \times 10^{-3}$ & 3.47 & $9.8 \times 10^{20}$ & $90.43 \%$ & $4.7 \times 10^{-3}$ & 3.42 \\
\hline
\end{tabular}

The differences of PVD-AZO film and PLD-AZO film in performance can be associated with the scattering effect and surface topographies. Therefore, an important investigation on roughness and crystallinity of these AZO films was carried out. Figure 2a shows the XRD (PANalytical, Almelo, The Netherlands) patterns of PVD-AZO and PLD-AZO. As we can see from the XRD patterns, PVD-AZO presents two sharp peaks at (002) and (103) planes, which implies the crystalline structure of this film is not preferentially oriented to the c-axis. Grain boundary scattering may occur in PVD-AZO films [23]. On the other hand, PLD-AZO film with amorphous structure is more suitable for large-scale preparation because of its high uniformity. As shown in Figure 2b,c, the root mean square (RMS) roughness of PVD-AZO is approximately $1.68 \mathrm{~nm}$, while that of PLD-AZO decreased to $1.15 \mathrm{~nm}$. The high energy of the laser may cause the decrease of roughness. The ablated particles have huge kinetic energy for migrating over the surface of the substrate, which contribute to a dense and smooth PLD-AZO film. Moreover, more carrier scattering caused by the rough surface of PVD-AZO will impair the conductivity of films.

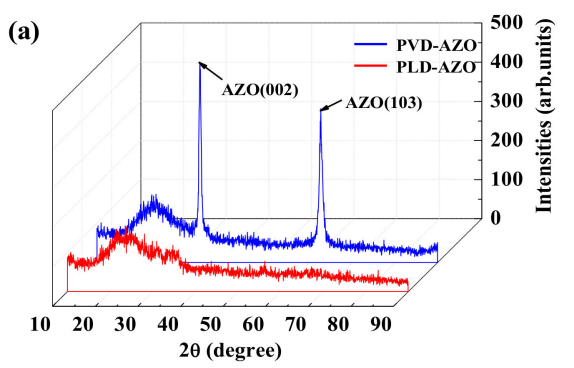

(b)

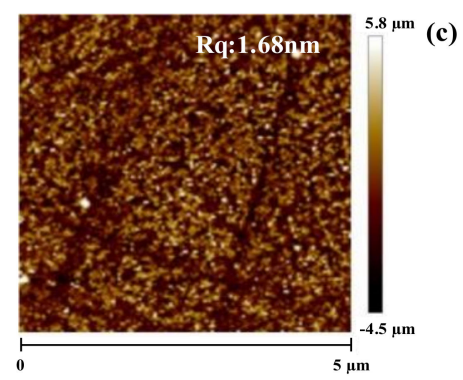

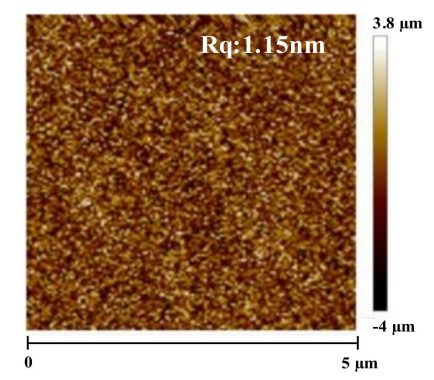

Figure 2. (a) XRD spectra of PVD-AZO and PLD-AZO; the surface topography of (b) PVD-AZO and (c) PLD-AZO.

As we observed from Figure $3 \mathrm{~b}$ and Table 1 , the resistivity of PLD-AZO $\left(1.6 \times 10^{-3} \Omega \cdot \mathrm{cm}\right)$ is nearly two times smaller than that of PVD-AZO $\left(2.64 \times 10^{-3} \Omega \cdot \mathrm{cm}\right)$, which indicates that the highly conductive PLD-AZO is more suitable for electrodes. Figure $3 c$ shows the Hall mobility $(\mu)$ and carrier concentration (n) of PVD-AZO and PLD-AZO. The increase of $\mu$ and $n$ of PLD-AZO may be 
attributed to the decrease of grain boundary scattering and the enhancement of oxygen vacancies, which can support the XRD and AFM (Multimode 8, Bruker, Billerica, MA, USA) results. The electrical properties of mental-oxide materials are mainly affected by oxygen vacancies. Figure $3 \mathrm{~d}$,e show the XPS (Thermo Fisher Scientific, Waltham, MA, USA) peak distribution curve of PVD-AZO and PLD-AZO. The O1 s peak can be divided into three peak components. The M-O-M peak centered at $\sim 530 \mathrm{eV}$ indicates the formation of a metal-oxygen-metal framework; the oxygen vacancies' peak $\left(\mathrm{V}_{\mathrm{O}}\right)$ centered at $\sim 531 \mathrm{eV}$ is reflecting to the oxide lattice with $\mathrm{V}_{\mathrm{O}}$, which is regarded as a critical factor affect the carrier concentration; the M-OR peak centered at $\sim 532 \mathrm{eV}$ is attributed to chemically adsorbed oxygen or water. The oxygen area proportion $\left(\mathrm{V}_{\mathrm{O}} /\left(\mathrm{V}_{\mathrm{O}}+\mathrm{V}_{\mathrm{M}-\mathrm{O}-\mathrm{M}}\right)\right)$ denotes the relative quantity of oxygen vacancy [24]. The value of $\mathrm{V}_{\mathrm{O}} /\left(\mathrm{V}_{\mathrm{O}}+\mathrm{V}_{\mathrm{M}-\mathrm{O}-\mathrm{M}}\right)$ is 0.35 for the PVD-AZO and significantly increases to 0.52 for the PLD-AZO. Thus, the XPS result shows that there are more oxygen vacancies in PLD-AZO film, corresponding to the high carrier concentration of $9.9 \times 10^{20} \mathrm{~cm}^{-3}$.
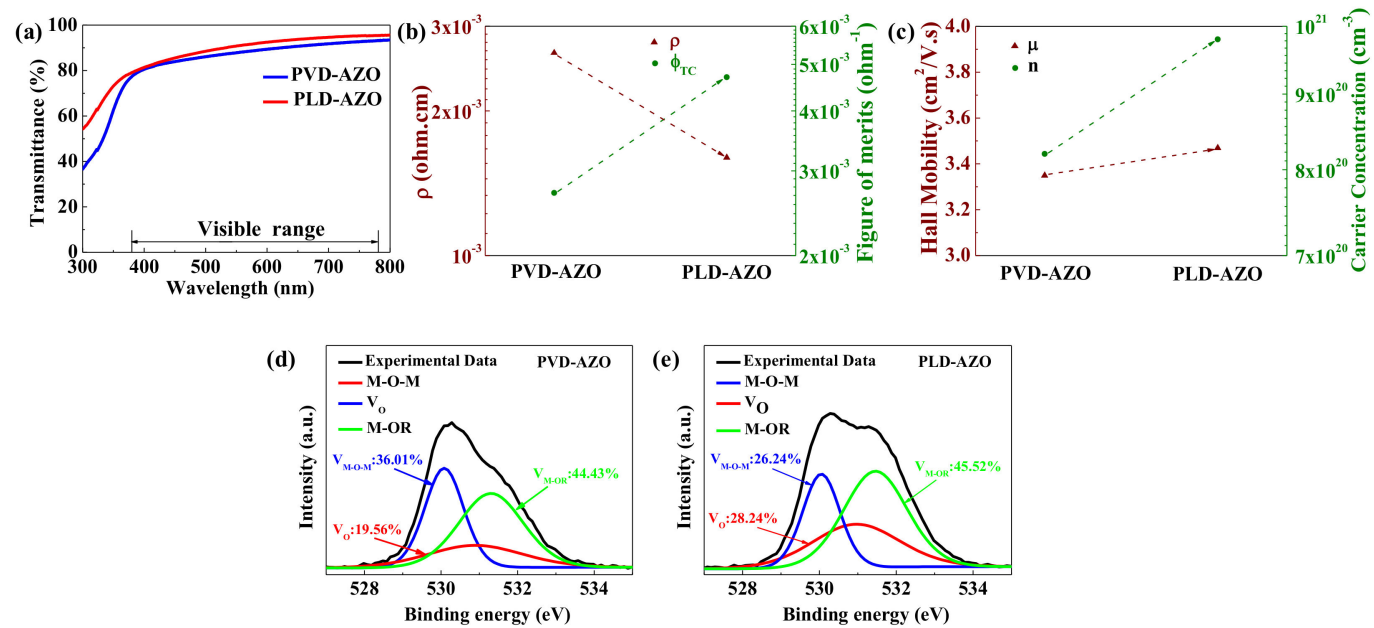

Figure 3. (a) The transmittance in the wavelength range of $300 \mathrm{~nm}-800 \mathrm{~nm}$ for PVD-AZO and PLD-AZO; (b) resistivity $(\varrho)$ and the figure of merits $\left(\Phi_{\mathrm{TC}}\right)$ of PVD-AZO and PLD-AZO; $(\mathbf{c})$ carrier concentration (n) and Hall mobility ( $\mu$ ) of PVD-AZO and PLD-AZO; the O1 s region of XPS spectra for (d) PVD-AZO and (e) PLD-AZO.

Another essential parameter that is measured to investigate whether the AZO films can be used in transparent display is the transmittance. Figure 3a shows the average transparency of PVD-AZO and PLD-AZO in the visible range is $88 \%$ and $90.43 \%$, respectively. PLD-AZO is superior in both resistivity and transmittance, which means the PLD method is the better way to prepare excellent TCOs compared with PVD. The figure of merit $\left(\Phi_{\mathrm{TC}}\right)$ is also a vital aspect to evaluating the quality of transparent conductive films. As shown in Figure $2 b$, the higher value of $\Phi_{\mathrm{TC}}\left(4.7 \times 10^{-3} \Omega^{-1}\right)$ of PLD-TFT implies the better quality transparent AZO film can be deposited by PLD. Overall, the AFM, XRD, Hall, and optical results demonstrate PLD is an ideal method for fabrication of transparent AZO $\mathrm{S} / \mathrm{D}$ electrodes with a dense, uniform, and smooth surface.

The bottom-gate TFTs with AZO S/D electrodes are further investigated in this paper. Figure 4 shows the transfer and output characteristics of these transparent TFTs and their corresponding respective parameters that we have measured are displayed in Table 2. As shown in Figure 4a, the PVD-AZO-TFT shows poor properties with a $\mu_{\text {sa }}$ t of $0.34 \mathrm{~cm}^{2} / \mathrm{V} \cdot \mathrm{s}$, an $\mathrm{I}_{\text {on }} / \mathrm{I}_{\text {off }}$ of $9.06 \times 10^{4}$, an SS of $1.104 \mathrm{~V} /$ decade, and a $\mathrm{V}_{\text {th }}$ of $6.36 \mathrm{~V}$. However, the PLD-AZO-TFT presents an excellent performance with a $\mu_{\text {sat }}$ of $8.59 \mathrm{~cm}^{2} / \mathrm{V} \cdot \mathrm{s}$, an $\mathrm{I}_{\text {on }} / \mathrm{I}_{\text {off }}$ of $4.13 \times 10^{6}$, an SS of $0.435 \mathrm{~V} /$ decade, and a $\mathrm{V}_{\text {th }}$ of $4.17 \mathrm{~V}$. Figure $4 b, c$ show the saturated output current of PVD-AZO-TFT and PLD-AZO-TFT is $0.4 \mu \mathrm{A}$ and $46.1 \mu \mathrm{A}$, respectively. The PLD-AZO-TFT has better output characteristics and excellent current driving ability. As a result, the PLD method has a great effect on improving the electrical properties of TFTs. 
(a)

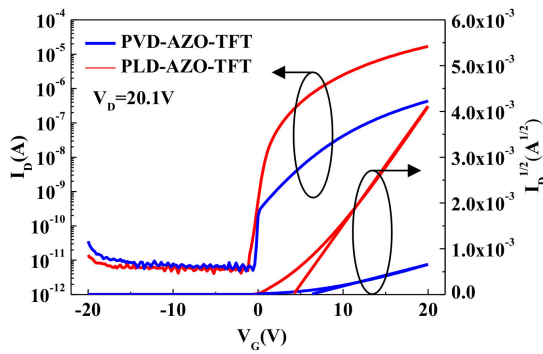

(c)

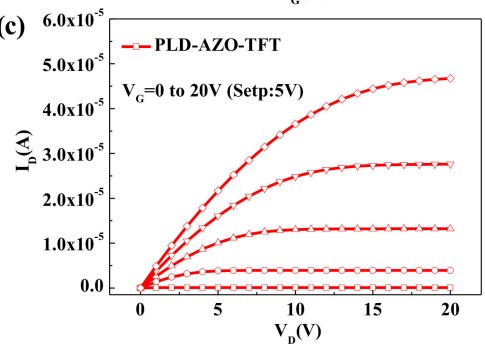

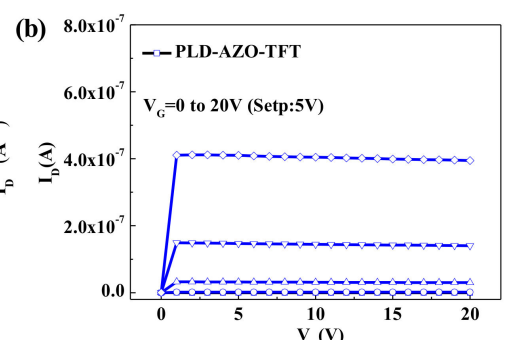

(d)

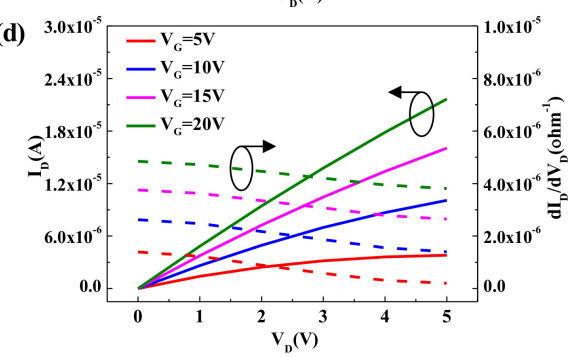

Figure 4. (a) Transfer characteristics of PVD-AZO-TFT and PLD-AZO-TFT; Output characteristics of (b) PVD-AZO-TFT and (c) PLD-AZO-TFT; (d) Output curve and its corresponding derivative curves in a linear region.

Table 2. Summary of the electrical properties of the PVD-AZO-TFT and PLD-AZO-TFT.

\begin{tabular}{ccccccc}
\hline Devices & $\begin{array}{c}\boldsymbol{\mu}_{\text {sat }} \\
\left(\mathbf{c m}^{2} / \mathbf{V} \cdot \mathbf{s}\right)\end{array}$ & $\mathbf{I}_{\text {on }} / \mathbf{I}_{\text {off }}$ & SS $(\mathbf{V} / \mathbf{d e c})$ & $\mathbf{R}_{\mathbf{S D}}(\mathbf{M} \Omega)$ & $\mathbf{V}_{\text {th }}(\mathbf{V})$ & $\begin{array}{c}\text { Output Current } \\
(\boldsymbol{\mu} \mathbf{A})\end{array}$ \\
\hline PVD-AZO-TFT & 0.34 & $9.06 \times 10^{4}$ & 1.104 & $1,1.7,3.8$ & 6.36 & 0.4 \\
PLD-AZO-TFT & 8.59 & $4.13 \times 10^{6}$ & 0.435 & 0.3 & 4.17 & 46.1 \\
\hline
\end{tabular}

The S/D contact properties is a critical aspect for the output performance in a linear region [25]. To investigate the reason of the favorable performance of PLD-AZO-TFT, we researched the output curve and its corresponding derivative curves in a linear region $\left(\mathrm{V}_{\mathrm{D}}=0-5 \mathrm{~V}\right)$. Figure $4 \mathrm{~d}$ shows the drain current linearly rose as $V_{D}$, and the differential conductance linearly decreased as $V_{D}$, which demonstrates the existence of high-quality ohmic contact in PLD-AZO-TFT. Additionally, the contact resistance can be obtained by the following formula of the transfer length method (TLM) [26].

$$
\mathrm{R}_{\mathrm{tot}}=\mathrm{V}_{\mathrm{DS}} / \mathrm{I}_{\mathrm{DS}}=\mathrm{L} \cdot \mathrm{r}_{\mathrm{ch}}+\mathrm{R}_{\mathrm{SD}},
$$

where $R_{t o t}, L, r_{c h}$, and $R_{S D}$ denote the total resistance, the length of the channel layer, the resistance of the channel per channel length unit, and the contact resistance, respectively. Then, $R_{S D}$ can be obtained from the $y$-axis intercept by plotting $R_{\text {tot }}$ as a function of L [27]. Figure 5a shows the $R_{S D}$ of PVD-AZO-TFT increased from $1 \mathrm{M} \Omega$ to $3.8 \mathrm{M} \Omega$ with the increase of $V_{G}$, which reveals there is no good ohmic contact between the $\mathrm{IGZO} / \mathrm{Al}_{2} \mathrm{O}_{3}$ and PVD-AZO S/D layers. However, as shown in Figure $5 b$, the PLD-AZO-TFT possesses excellent performance owing to the $\mathrm{R}_{\mathrm{SD}}$ keeping a constant value of $0.3 \mathrm{M} \Omega$ at different $\mathrm{V}_{\mathrm{G}}$. The optical band gaps of $\mathrm{AZO}$ films and the $\mathrm{IGZO} / \mathrm{Al}_{2} \mathrm{O}_{3}$ bi-layer are fitted to study the differences in the contact resistance. The $\mathrm{E}_{\mathrm{g}}$ of films can be calculated by the following formula:

$$
\alpha \mathrm{h} v=\mathrm{C}\left(\mathrm{h} v-\mathrm{E}_{\mathrm{g}}\right)^{1 / 2}
$$

where $\alpha$ is the optical absorption coefficient, $E_{g}$ is the band-gap energy, and hv is the photon energy [28]. The plot of $(\alpha h v)^{2}$ versus $h v$ is shown in Figure $5 \mathrm{c}$. The $\mathrm{E}_{\mathrm{g}}$ can be obtained by fitting the straight-line portion of the plot. The value of $\mathrm{E}_{\mathrm{g}}$ of PVD-AZO, PLD-AZO, and $\mathrm{IGZO} / \mathrm{Al}_{2} \mathrm{O}_{3}$ multi-layer is $3.3 \mathrm{eV}, 3.42 \mathrm{eV}$, and $3.65 \mathrm{eV}$, respectively. Based on this result, Figure $5 \mathrm{~d}$ shows the schematic of the electron transport between $\mathrm{AZO}$ films and the $\mathrm{IGZO} / \mathrm{Al}_{2} \mathrm{O}_{3}$ multi-layer, and the electron transport of PLD-AZO-TFT is smoother than that of PVD-AZO-TFT. This result indicates potential barriers impeding the electron transport are almost non-existent in PLD-AZO-TFT, due to a tiny difference of 
$\mathrm{E}_{\mathrm{g}}$ between the active layer and S/D electrodes. Therefore, the $\mathrm{R}_{\mathrm{SD}}$ of PLD-AZO-TFT has a relatively small value, which is related to the lower barrier.
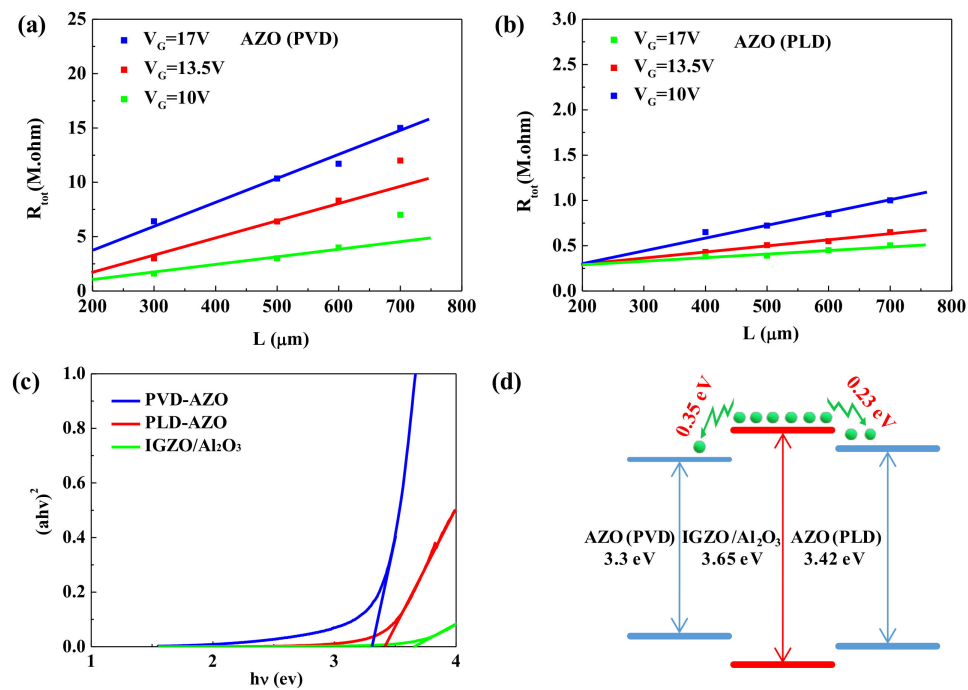

(d)

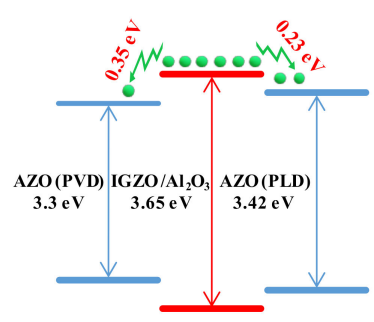

Figure 5. Total resistance as a function of the channel length at various $\mathrm{V}_{\mathrm{GS}}$ for (a) PVD-AZO-TFT and

(b) PLD-AZO-TFT; (c) plot of $(\alpha \mathrm{h} v)^{2}$ versus $\mathrm{h} v$ for PVD-AZO, PLD-AZO, and $\mathrm{IGZO} / \mathrm{Al}_{2} \mathrm{O}_{3}$ multi-layer;

(d) schematic of the electron transport between $\mathrm{AZO}$ films and the $\mathrm{IGZO} / \mathrm{Al}_{2} \mathrm{O}_{3}$ bi-layer.

The gate-bias stability of PVD-AZO-TFT and PLD-AZO-TFT were both measured and the results are displayed in Figure $6 \mathrm{a}-\mathrm{d}$. These devices were applied positive gate-bias stress (PBS) under $V_{G S}=+10 \mathrm{~V}$ for one hour and negative gate-bias stress (NBS) under $V_{G S}=-10 \mathrm{~V}$ for one hour. The $V_{\text {on }}$ shift of these TFTs under the PBS and NBS measurements are compared in Figure 6e. It is evident that the $\mathrm{V}_{\text {on }}$ shifts of the PVD-AZO-TFT under PBS closely coincide with that of the PLD-AZO-TFT. The $\mathrm{V}_{\text {on }}$ shifts of the PLD-AZO-TFT under NBS are smaller than that of PVD-AZO-TFT. The NBS/PBS shifts are mainly affected by the quality of the insulator and channel layer. RF magnetron sputtering mainly relies on $\mathrm{Ar}^{+}$ions' bombard target. Few $\mathrm{Ar}^{+}$ions may damage the channel layer, which brings out the relatively poor stability of PVD-AZO-TFT. Nonetheless, there is no ion damage in PLD, and the quality of the channel layer of PLD-AZO-TFT is better than that of PVD-AZO-TFT. Moreover, the ablated particles have huge kinetic energy due to the laser of PLD possessing high energy. Thus, PLD-AZO-TFT exhibit better PBS/NBS stability.
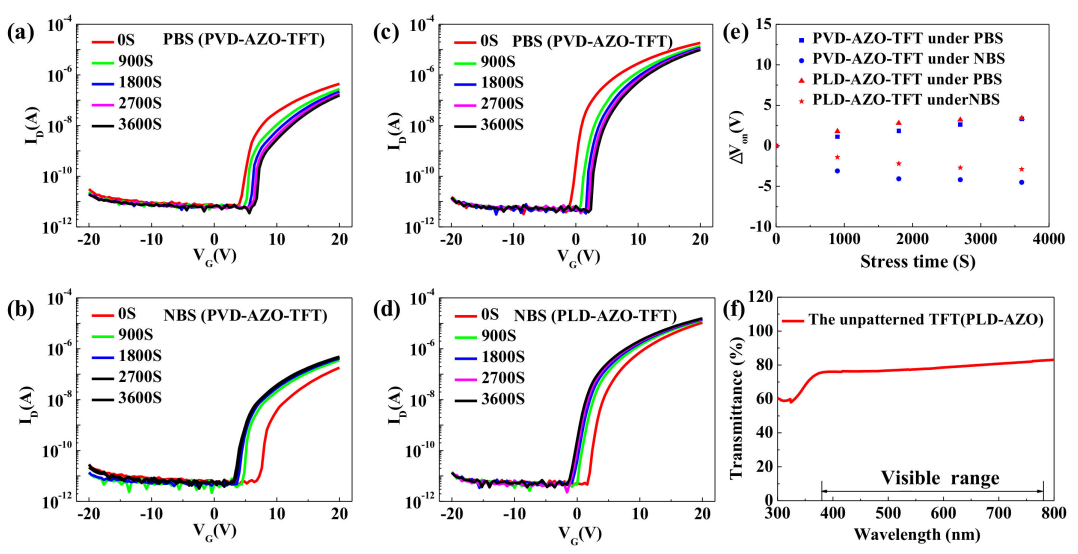

Figure 6. (a) PBS and (b) NBS results of the PVD-AZO-TFT; (c) PBS and (d) NBS results of the PLD-AZO-TFT; (e) the $\mathrm{V}_{\mathrm{on}}$ shift of the TFTs under PBS $(\mathrm{VG}=+10 \mathrm{~V})$ and NBS $(\mathrm{VG}=-10 \mathrm{~V})$; (f) transmittance spectra in the wavelength range of $300 \mathrm{~nm}-800 \mathrm{~nm}$ for un-patterned TFTs. 
The transparency of PLD-AZO-TFT was investigated to verify the feasibility in the transparent display. Figure $6 \mathrm{f}$ shows the transparency of the un-patterned PLD-AZO-TFT can reach $78.5 \%$. Highly transparent PLD-AZO-TFT has huge potential in the field of transparent display.

\section{Conclusions}

In summary, high-performance transparent TFT with high-quality AZO source/drain electrodes was successfully fabricated by the PLD method. The resistivity, transparency, AFM, XRD, Hall, and contact resistance properties reveal different ways have great influence on dense, uniform, surface roughness, and carrier concentration of AZO films. The AZO films fabricated by the PLD method at room temperature, which possessed an exceptional quality, a resistivity of $1.6 \times 10^{-3} \Omega \cdot \mathrm{cm}$, and a transmittance of $90.43 \%$, can almost reach or even exceed that of ITO (resistivity: $6 \times 10^{-4} \Omega \cdot \mathrm{cm}$; transparency: 85\%) [29]. Non-toxic AZO film has great potential as a promising alternative to ITO and used in the field of environmental protection. More remarkable, TFTs with the optimized PLD-AZO electrodes exhibited excellent performance $\left(\mu_{\text {sat }}: 8.59 \mathrm{~cm}^{2} / \mathrm{V} \cdot \mathrm{s}, \mathrm{I}_{\text {on }} / \mathrm{I}_{\text {off }}: 4.13 \times 10^{6}\right.$, SS: $0.435 \mathrm{~V} /$ decade, $\mathrm{R}_{\mathrm{SD}}$ : $0.3 \mathrm{M} \Omega$, transparency: $78.5 \%$ ), and good stability under NBS/PBS. The fabrication of this transparent TFT is desired for the transparent displays industry.

Author Contributions: Methodology: H.Z.; resources: R.Y.; supervision: X.L., Z.F., X.Z., Y.D., X.L., H.T., H.N., and J.P.; writing (original draft): H.Z.; writing (review and editing): H.Z.

Funding: This work was supported by National Natural Science Foundation of China (Grant. 51771074, 51521002 and U1601651), National Key Basic Research and Development Program of China (973 program, Grant No. 2015CB655004) Founded by MOST, Guangdong Natural Science Foundation (No. 2016A030313459 and 2017A030310028), Guangdong Science and Technology Project (No. 2016B090907001, 2016A040403037, 2016B090906002, 2017B090907016 and 2017A050503002), Guangzhou Science and Technology Project (201804020033) and the Project for Guangdong Province Universities and Colleges Pearl River Scholar Funded Scheme (2016).

Conflicts of Interest: The authors declare no conflict of interest.

\section{References}

1. Hoffman, R.L.; Norris, B.J.; Wager, J.F. Zno-based transparent thin-film transistors. Appl. Phys. Lett. 2003, 82, 733-735. [CrossRef]

2. Fortunato, E.; Barquinha, P.; Pimentel, A.; Gonçalves, A.; Marques, A.; Pereira, L.; Martins, R. Recent advances in $\mathrm{ZnO}$ transparent thin film transistors. Thin Solid Films 2005, 487, 205-211. [CrossRef]

3. Chiang, H.Q.; Wager, J.F.; Hoffman, R.L. High mobility transparent thin-film transistors with amorphous zinc tin oxide channel layer. Appl. Phys. Lett. 2005, 86, 1624-1621. [CrossRef]

4. Dehuff, N.L.; Kettenring, E.S.; Hong, D.; Chiang, H.Q.; Wager, J.F.; Hoffman, R.L.; Park, C.H.; Keszler, D.A. Transparent thin-film transistors with zinc indium oxide channel layer. J. Appl. Phys. 2005, 97, 064505. [CrossRef]

5. Kenji, N.; Hiromichi, O.; Akihiro, T.; Toshio, K.; Masahiro, H.; Hideo, H. Room-temperature fabrication of transparent flexible thin-film transistors using amorphous oxide semiconductors. Nature 2004, 432, 488-492. [CrossRef]

6. Su, S.H.; Wu, C.M.; Tsai, H.L.; Yokoyama, M. Transparent organic thin film transistors using an oxide/metal/oxide trilayer as low-resistance transparent source/drain electrodes. Jpn. J. Appl. Phys. 2013, 52, 04CK09. [CrossRef]

7. Park, S.H.K.; Hwang, C.S.; Ryu, M.; Yang, S.; Byun, C.; Shin, J.; Lee, J.I.; Lee, K.; Min, S.O.; Im, S. Transparent and photo-stable zno thin-film transistors to drive an active matrix organic-light-emitting-diode display panel. Adv. Mater. 2010, 21, 678-682. [CrossRef]

8. Fang, G.; Li, D.; Yao, B.L. Fabrication and vacuum annealing of transparent conductive azo thin films prepared by dc magnetron sputtering. Vacuum 2002, 68, 363-372. [CrossRef]

9. Chipman, A. A commodity no more. Nature 2007, 449, 131. [CrossRef]

10. Maghanga, C.M.; Niklasson, G.A.; Granqvist, C.G. Optical properties of sputter deposited transparent and conducting $\mathrm{Tio}_{2}$ : $\mathrm{Nb}$ films. Thin Solid Films 2009, 518, 1254-1258. [CrossRef] 
11. Chen, T.L.; Furubayashi, Y.; Hirose, Y.; Hitosugi, T.; Shimada, T.; Hasegawa, T. Anatase phase stability and doping concentration dependent refractivity in codoped transparent conducting $\mathrm{Tio}_{2}$ films. J. Phys. D Appl. Phys. 2007, 40, 5961. [CrossRef]

12. Minami, T. Present status of transparent conducting oxide thin-film development for indium-tin-oxide (ITO) substitutes. Thin Solid Films 2008, 516, 5822-5828. [CrossRef]

13. Murdoch, G.B.; Hinds, S.; Sargent, E.H.; Tsang, S.W.; Mordoukhovski, L.; Lu, Z.H. Aluminum doped zinc oxide for organic photovoltaics. Appl. Phys. Lett. 2009, 94, 138. [CrossRef]

14. Miyata, T.; Ohtani, Y.; Kuboi, T.; Minami, T. Stability of nano-thick transparent conducting oxide films for use in a moist environment. Thin Solid Films 2008, 516, 1354-1358. [CrossRef]

15. Ruske, F.; Roczen, M.; Lee, K.; Wimmer, M.; Gall, S.; Hupkes, J.; Hrunski, D.; Rech, B. Improved electrical transport in al-doped zinc oxide by thermal treatment. J. Appl. Phys. 2010, 107, 242-1790. [CrossRef]

16. Greiner, D.; Papathanasiou, N.; Pflug, A.; Ruske, F.; Klenk, R. Influence of damp heat on the optical and electrical properties of al-doped zinc oxide. Thin Solid Films 2009, 517, 2291-2294. [CrossRef]

17. Lin, W.; Ma, R.; Xue, J.; Kang, B. Rf magnetron sputtered zno: Al thin films on glass substrates: A study of damp heat stability on their optical and electrical properties. Sol. Energy Mater. Sol. Cells 2007, 91, 1902-1905. [CrossRef]

18. Sankir, N.D.; Aydin, E.; Ugur, E.; Sankir, M. Non-toxic and environmentally friendly route for preparation of copper indium sulfide based thin film solar cells. J. Alloys Compd. 2015, 640, 468-474. [CrossRef]

19. Jin, M. Optical and electronic properties of transparent conducting $\mathrm{ZnO}$ and $\mathrm{ZnO}$ : Al films prepared by evaporating method. Thin Solid Films 1999, 357, 98-101. [CrossRef]

20. Jin, B.J.; Woo, H.S.; Im, S.; Bae, S.H.; Lee, S.Y. Relationship between photoluminescence and electrical properties of zno thin films grown by pulsed laser deposition. Appl. Surf. Sci. 2001, 169, 521-524. [CrossRef]

21. Park, D.C.; Fujita, S.; Fujita, S. Growth of polycrystalline GaN on silicon (001) substrates by RF plasma chemical vapor deposition with $\mathrm{ZnO}$ buffer layer. Phys. Status Solidi 1999, 176, 579-582. [CrossRef]

22. Yao, R.; Zheng, Z.; Fang, Z.; Zhang, H.; Zhang, X.; Ning, H.; Wang, L.; Peng, J.; Xie, W.; Lu, X. High-performance flexible oxide TFTs: Optimization of a-IGZO film by modulating voltage waveform of pulse DC magnetron sputtering without post treatments. J. Mater. Chem. C 2018, 6, 2522-2532. [CrossRef]

23. Marom, H.; Ritterband, M.; Eizenberg, M. The contribution of grain boundary scattering versus surface scattering to the resistivity of thin polycrystalline films. Thin Solid Films 2006, 510, 62-67. [CrossRef]

24. Lee, S.; Bang, S.; Park, J.; Park, S.; Jeong, W.; Jeon, H. The effect of oxygen remote plasma treatment on zno tfts fabricated by atomic layer deposition. Phys. Status Solidi 2010, 207, 1845-1849. [CrossRef]

25. Kumomi, H.; Kanicki, J.; Abe, K.; Fung, T.C. Electrical instability of RF sputter amorphous In-Ga-Zn-O thin-film transistors. J. Disp. Technol. 2009, 5, 452-461. [CrossRef]

26. Schroder, D.K. Semiconductor Material and Device Characterization; Wiley: Hoboken, NJ, USA, 1998; pp. 107-108.

27. Kim, W.S.; Moon, Y.K.; Kim, K.T.; Lee, J.H.; Ahn, B.D.; Park, J.W. An investigation of contact resistance between metal electrodes and amorphous gallium-indium-zinc oxide (a-GIZO) thin-film transistors. Thin Solid Films 2010, 518, 6357-6360. [CrossRef]

28. Tauc, J.; Grigorovici, R.; Vancu, A. Optical properties and electronic structure of amorphous germanium. Phys. Status Solidi (b) 1966, 15, 627-637. [CrossRef]

29. Shin, J.H.; Shin, S.H.; Park, J.I.; Kim, H.H. Properties of dc magnetron sputtered indium tin oxide films on polymeric substrates at room temperature. J. Appl. Phys. 2001, 89, 5199-5203. [CrossRef]

(C) 2018 by the authors. Licensee MDPI, Basel, Switzerland. This article is an open access article distributed under the terms and conditions of the Creative Commons Attribution (CC BY) license (http://creativecommons.org/licenses/by/4.0/). 